\title{
"Para no trabajar de sol a sol" Los sentidos de la educación en jóvenes y adultos/as integrantes de familias migrantes bolivianas hortícolas del Gran La Plata - Buenos Aires, Argentina
}

\section{Soledad Lemmi}

CONICET. Instituto de Investigaciones en Humanidades y Ciencias Sociales (IdIHCS) Universidad Nacional de La Plata. La Plata, Argentina.

CONICET. Centro de Investicaciones sobre Economía y Sociedad en la Argentina Contemporánea (IESAC) Universidad Nacional de Quilmes. Bernal, Argentina.

Correo electrónico de contacto: soledadlemmi@yahoo.com

\section{Melina Morzilli}

Universidad Nacional Arturo Jauretche. Florencio Varela, Argentina.

CONICET. Instituto de Investigaciones en Humanidades y Ciencias Sociales (IdIHCS) Universidad Nacional de La Plata. La Plata, Argentina.

Correo electrónico: melinamorzilli@gmail.com

\section{Ornella Moretto}

CONICET. Instituto de Investigaciones en Humanidades y Ciencias Sociales (IdIHCS) Universidad Nacional de La Plata. La Plata, Argentina.

Correo electrónico: orne.moretto@gmail.com

\section{Resumen}

En este trabajo nos proponemos indagar acerca de los sentidos que construyen respecto de la educación las familias productoras de hortalizas del Gran La Plata. Estas están compuestas mayoritariamente de adultos/as migrantes de origen boliviano y sus hijos/as bolivianos/as y argentinos/as. En dicho sentido, abordaremos la significación que le otorgan a la escolaridad, tanto en casos de adultos que deciden retomar sus estudios primarios y secundarios, como de jóvenes que se encuentran atravesando los estudios secundarios. Asimismo, analizamos las estrategias que ponen en juego para cumplimentar la escolarización en función de dichos sentidos. La información fue recabada a partir de una metodología de carácter cualitativa basada en el trabajo etnográfico. Adelantamos aquí los sentidos que adquiere la educación para estas familias, tanto de los/as adultos/as como de jóvenes, como una estrategia de sociabilidad extra quinta, así como una posibilidad a futuro de mejora de sus condiciones materiales de vida.
Recibido:

17 de enero de 2018 Aceptado:

27 de junio de 2018

\section{Palabras clave}

Educación; Horticultores; Migrantes; Bolivianos; Argentina 


\section{"To not work from sunrise to sunset". The senses of educa- tion in young and adult members of Bolivia's horticultural migrant families of Gran La Plata - Buenos Aires, Argentina}

\section{Abstract}

Key words

Education; Horticulturists; Migrants; Bolivians; Argentina

In this work we propose to investigate about the senses that the families that produce vegetables from Gran La Plata build with regard to education. They are composed mostly of migrant adults of Bolivian origin and their Bolivian and Argentine children. In this sense we will address the significance that they give to schooling both in cases of adults who decide to resume their primary and secondary education and of young people who are going through secondary school. Likewise, we analyze the strategies that they put into play to complete schooling according to these senses. The information was gathered from a qualitative methodology based on ethnographic work. We advance here the senses acquired by education for these families, both of adults and young people, as a strategy of extra-fifth sociability as well as a future possibility of improving their material conditions of life.

\section{"Para não trabalhar do nascer ao pôr do sol". Os sentidos da educação em jovens e adultos membros das famílias de mi- grantes hortícolas da Bolívia de Gran La Plata - Buenos Aires, Argentina}

\section{Resumo}

Palavras-chave

Educação; Horticultores; Migrantes; Bolivianos; Argentina
1. En concordancia con los avances en materia de género de las últimas décadas -que abarcan, entre otras cosas, el uso de un lenguaje inclusivo- utilizaremos en el presente trabajo el recurso "os/ as" en todos los casos en los que haremos referencia a la población considerada en la investigación, con el objetivo de no invisibilizar la referencia a las mujeres bajo un lenguaje que generaliza desde lo masculino. Si bien reconocemos que este recurso no es totalmente inclusivo, en tanto no considera otras identidades de género, sí creemos que es representativo de esta pequeña población compuesta por personas que se reconocen a sí mismas como varones o mujeres.
Neste trabalho propomos investigar sobre os sentidos que as famílias produtoras de hortaliças de Gran La Plata constroem em relação à educação. Eles são compostos principalmente de adultos migrantes de origem boliviana e suas crianças bolivianas e argentinas. Nesse sentido, abordaremos o significado que eles dão à escolarização, tanto nos casos de adultos que decidem retomar o ensino fundamental e médio, quanto de jovens que estão cursando o ensino médio. Da mesma forma, analisamos as estratégias que eles colocam em prática para completar a escolarização de acordo com esses sentidos. As informações foram coletadas a partir de uma metodologia qualitativa baseada no trabalho etnográfico. Avançamos aqui os sentidos adquiridos pela educação para essas famílias, tanto de adultos quanto de jovens, como uma estratégia de sociabilidade extra-quinta, bem como uma possibilidade futura de melhorar suas condições materiais de vida.

\section{Introducción}

En este trabajo nos proponemos reconstruir los sentidos que los/las jóvenes y adultos/as ${ }^{1}$ integrantes de familias productoras de hortalizas del Gran La Plata construyen en torno a la educación. Asimismo, analizamos las estrategias que ponen en juego para cumplimentar la escolarización en función de dichos sentidos. Este escrito forma parte de una investigación mayor que venimos 
desarrollando hace varios años, en la cual exploramos los diferentes componentes que construyen las trayectorias ${ }^{2}$ educativas de familias integradas por migrantes horticultores/as platenses. ${ }^{3}$

Cuando comenzamos la investigación partimos de estudios referentes sobre el periurbano hortícola platense. Estos nos indicaban que los/las sujetos con los que íbamos a interactuar en el campo de estudio provenían de sectores populares, que se encontraban en situación de vulnerabilidad social y pobreza, y que pertenecían a hogares que se dedicaban a la agricultura familiar. Esto implicaba que sus miembros, tanto jóvenes como adultos/as, debían trabajar para sostener la reproducción del grupo familiar (Attademo, 2009; Ringuelet, 2009). En este contexto, nos preguntamos cómo serían las trayectorias escolares de jóvenes y adultos/as integrantes de familias que se dedican a la horticultura. Las diferentes líneas de investigación sobre trayectorias educativas nos indicaban la posibilidad de arribar a resultados disímiles.

Un conjunto de estudios dieron cuenta de fenómenos dentro de las familias, que, articulados, configuraban un escenario en el cual las trayectorias escolares culminan en la desescolarización sin que esto implique conflictos intrafamiliares y frustración de expectativas. Esto se puede observar en las altas tasas de escolarización en las edades propias de la educación primaria que muestran que las familias buscan que sus niños pasen por la experiencia escolar; mientras que esta valoración tiende a decaer cuando se trata de la educación media. Para muchos padres y madres es aceptable que sus hijos adolescentes dejen la escuela, incluso en muchos casos los acompañan en su decisión y se hacen cómplices de ella (Sistema de Información de Tendencias Educativas en América Latina, 2009; Binstock y Cerrutti, 2012; Briscioli, 2013).

Otros estudios, por su parte, se focalizaron en investigar los sentidos que adquiere el pasaje por la escuela para los diferentes miembros de familias de los sectores populares, así como de las múltiples estrategias que estos ponen en juego para cumplimentar sus metas educativas. Lejos de cualquier reducto simplificador y reproductivista, estas investigaciones nos alertan acerca de los múltiples saberes y experiencias que los y las estudiantes de sectores populares adquieren en el proceso de escolarización; así como de la significación positiva que dicho pasaje posee para ellos/as, en tanto obran de múltiples maneras y en ocasiones a contramarcha de sus propias imposibilidades, sorteando obstáculos o mandatos sociales devenidos de su posición de clase (Santillán, 2009, 2012; Cerletti, 2010, 2014).

A partir de lo descrito, nos preguntamos particularmente por los sentidos que le otorgan a la educación las y los jóvenes que se encuentran atravesando los estudios secundarios, así como los que les dan los y las adultos/as que deciden retomar sus estudios primarios y secundarios integrantes de familias hortícolas platenses. A su vez, observamos las estrategias que despliegan las familias en ambos casos para alcanzar las credenciales educativas.

Las escuelas secundarias a las que asisten los/as sujetos que son objeto de este estudio (una escuela de nivel medio de gestión estatal y dos bachilleratos de adultos bajo la modalidad FinEs) ${ }^{4}$ se ubican en el periurbano hortícola platense y poseen la particularidad que asisten a ellas un porcentaje relevante (más de la mitad de la matrícula) de estudiantes migrantes bolivianos/as o hijos/as de migrantes.
2. En este trabajo se toma el concepto //*la noción// de trayectorias como concepto mediador, ya que posee una potencialidad para unir en el análisis la historicidad de los procesos sociales, las constricciones estructurales y la agencia de los agentes (Waisman, 2012).

3. Proyecto de I+D “Reconfiguraciones en el espacio rural bonaerense: estrategias familiares de reproducción social, trayectorias laborales y educativas y procesos de sociabilidad en el periurbano platense, Necochea y Junín" (Centro de Historia Argentina y Americana; Instituto de Investigaciones en Humanidades y Ciencias Sociales; Facultad de Humanidades y Ciencias de la Educación; Universidad Nacional de La Plata-CONICET) dirigido por la Lic. Silvia Attademo.

4. El Programa de Finalización de Estudios Primarios y Secundarios para Jóvenes y Adultos es un programa nacional aplicado en el país desde el año 2008. Además de ser implementado en los barrios periféricos por medio de organizaciones sociales y políticas, propone un dispositivo de cursada accesible y de menor duración, que consta de cuatro meses - para la finalización de los estudios primarios-y de tres años para la finalización de los estudios secundarios. 
5. Resulta importante destacar que, si bien se ha conceptualizado a la horticultura como una economía de enclave étnico o economía étnica -haciendo alusión al casi total componente migrante boliviano en la fuerza de trabajo en el sector a lo largo de todo el país-, en el caso platense los trabajadores no tienden a agruparse colectivamente por su origen étnico-nacional boliviano, sino por su adscripción productiva en tanto horticultores. En dicho sentido, ser horticultor/a es un adscripción que posee más fuerza que el hecho de ser bolivianos/as al momento de desarrollar lazos de sociabilidad y comunalidad.
Es importante señalar que hacia mediados de los años ochenta comenzaron a arribar al periurbano hortícola platense (provincia de Buenos Aires), en búsqueda de trabajo, migrantes andinos/as de origen boliviano. Provenientes de Tarija, Cochabamba, Chuquisaca y Potosí, y de origen campesino, trajeron consigo los conocimientos que habían sido transmitidos de generación en generación sobre las labores rurales. Y si bien el trabajo en la quinta posee características diferentes (invernaderos, tecnología de riego, semillas híbridas, uso de agroquímicos, entre otras), el hecho de saber trabajar la tierra, vivir "en el campo" con todo lo que ello implica, y producir para la subsistencia, les permitió adaptarse rápidamente a las nuevas condiciones laborales (Ringuelet, 2000; Benencia, Quaranta y Souza Casadinho, 2009; García, 2012, 2014; Castro, 2016). Los/as migrantes andinos/as hicieron su trayecto al periurbano hortícola platense como familia, y muchas de ellas fueron ampliando sus miembros con hijos e hijas nacidas en Argentina. La masiva presencia de estos/as migrantes en la horticultura ha llevado a conceptualizar dicho espacio productivo como economía de enclave étnico. ${ }^{5}$ En la actualidad, su trabajo abastece la demanda de hortalizas de 20 millones de habitantes ubicados mayoritariamente en el área metropolitana de Buenos Aires, pero también del resto del país (Benencia, Ramos y Salusso, 2016).

A partir de las singularidades que poseen los/las jóvenes y adultos/as migrantes bolivianos/as insertos/as en este contexto territorial y productivo específico, es que intentamos contribuir al debate acerca de las significaciones que los sectores populares construyen en relación con la educación y qué estrategias ponen en juego en función de dichos sentidos para cumplimentar sus metas educativas. En el caso que aquí investigamos, las diferentes formas en que dichos/as sujetos encaran sus metas escolares nos advierten acerca de lo difícil de cualquier simplificación en el análisis y explicación de la realidad indagada. Las intersecciones de origen, clase y etnia nos alertan de las diferentes y desiguales posiciones que los y las sujetas investigadas poseen, pero también nos habilitan a pensar las múltiples formas de resistencia que llevan adelante los sectores subalternos para romper el círculo de la reproducción (Willis, 1988; Levinson y Holland, 1996).

A su vez, es nuestro interés poner en diálogo los resultados de este trabajo con investigaciones ya existentes sobre el tema que han centrado su mirada en la educación de la población boliviana (Salazar de la Torre, 2008), y aquella en particular que migra a la Argentina y se dedica a diversos oficios en múltiples regiones del país (Kraser y Ockier, 2008; Gavazzo, Beheran y Novaro, 2014; Diez, 2014; Gago y Maggi, 2018).

En adelante, se desarrollarán el marco teórico, la metodología y las fuentes; posteriormente se describirán las características que poseen las familias migrantes bolivianas a las que pertenecen los/las jóvenes y adultos /as sujetos de esta investigación, contextualizando su llegada e inserción en la ciudad y en la producción hortícola en particular; a continuación se analizarán los sentidos que los/las jóvenes y adultos/as construyen en torno a la educación y las estrategias que como familias horticultoras ponen en juego a partir de dichas significaciones; finalmente, se esbozan algunas reflexiones finales.

\section{Acerca de cómo se construyó esta investigación}

En cuanto al marco teórico que orienta el presente trabajo, a partir del estudio de los sentidos intentamos dar cuenta de las representaciones sociales, la 
perspectiva de los actores acerca del lugar que le atribuyen a la educación en sus estrategias familiares de vida. Nos interesa rescatar la dimensión discursiva, simbólica, de aquellas representaciones sociales que son manifestadas en los relatos de los/las jóvenes y adultos/as investigados/as (Jodelet, 1989). Representaciones que distan de ser individuales pero que son, en definitiva, a las que recurren los y las sujetas en cuestión para tomar sus decisiones. El anclaje de estas en la propia posición estructural que ellos/as ocupan no descarta la dimensión cultural que subyace en toda decisión individual (Giménez Montiel, 2005).

Asimismo, retomamos la propuesta teórica de Pierre Bourdieu, quien, al hablar de estrategias, las conceptualiza como las prácticas (productivas, culturales, políticas, etc.) por medio de las cuales los agentes individuales o colectivos tienden, consciente o inconscientemente, a conservar o aumentar su patrimonio, para así conservar o mejorar su posición en la estructura de relaciones de clase (Bourdieu, 1988, 1990, 1991).

Teniendo en cuenta los objetivos de la presente investigación, se implementarán diversas estrategias de aproximación al objeto de estudio para dar cuenta de la problemática planteada, privilegiando la perspectiva cualitativa en el análisis de la documentación empírica. Por tanto, se opta por una investigación histórico-etnográfica por ser la más adecuada, dado el proceso de participación y el tipo de acercamiento a los actores sociales; en la que se pretende reconstruir la perspectiva de los sujetos sociales acerca de las acciones que protagonizan, en su papel de intérpretes polémicos del mundo social (Batallán y García, 1992; Guber, 2001; Rockwell, 2009). Desde el abordaje metodológico etnográfico, se llevarán adelante observaciones participantes y entrevistas en profundidad (semiestructuradas) a interlocutores seleccionados a partir de una muestra teórica intencionada conformada por bola de nieve. Esta metodología nos permitirá reconstruir la perspectiva del actor social rescatando el sentido otorgado a las prácticas y, de modo particular, aquellas referidas a las metas educativas de jóvenes y adultos/as integrantes de familias bolivianas del cinturón hortícola platense.

La información para responder a los interrogantes que nos planteamos ha sido recabada y coconstruida a partir de diferentes fuentes. La reconstrucción de los sentidos que le otorgan a la educación los/las jóvenes y sus madres y las estrategias que despliegan en dicho sentido pudo realizarse a partir del contacto que se generó mediante trabajos de extensión universitaria efectuados desde la facultad a la que pertenecemos (FaHCE-UNLP). ${ }^{6}$ Mientras que la reconstrucción de los sentidos otorgados a la educación por los/las adultos/as y las prácticas desplegadas por ellos fue elaborada a partir de nuestra participación hace varios años en dos movimientos de productores/as de la región.

El proyecto de extensión se lleva a cabo en una escuela secundaria ubicada en Ángel Etcheverry (localidad perteneciente al periurbano platense), en la cual el $60 \%$ de los/as estudiantes son de origen boliviano o hijos/as de bolivianos/ as. Dicho establecimiento forma parte de un entramado escolar que incluye el jardín de infantes y la escuela primaria, todos en terrenos contiguos y que articulan entre sí los pasos de nivel (jardín a primaria y primaria a secundaria). El trabajo de extensión en la institución educativa se inició en el año 2015, momento a partir del cual comenzamos una exploración etnográfica profunda e interactuamos con estudiantes en una gran parte de su trayecto por la escuela secundaria. Durante los años 2016 y 2017 efectuamos entrevistas en profundidad a 21 estudiantes de segundo a sexto año y a sus madres; también
6. Facultad de Humanidades y Ciencias de la Educación- Universidad Nacional de La Plata. 
realizamos junto con los/las jóvenes y sus madres un calendario de trayectorias educativas donde se señalaron los diferentes momentos e hitos en esa trayectoria (ingreso a las instituciones educativas, cambios de escuela, motivos de los cambios como mudanzas, migraciones, enfermedades, etc.) (Nelson, 2010; Briscioli, 2013). La calendarización de las trayectorias fue acompañada de una encuesta acerca de las condiciones de vida de los/las estudiantes y madres en cuestión.

En la misma institución, en 2017 se realizó, en cuarto año, un taller a partir del cual los/las estudiantes dieron cuenta de la transmisión intergeneracional del oficio de horticultor/a, las relaciones intrafamiliares vinculadas al trabajo en la quinta y las proyecciones una vez terminada la escuela. Posteriormente, durante 2018 se llevaron a cabo tres talleres en quinto y sexto año, donde los estudiantes reconstruyeron su trayectoria educativa y perspectivas a futuro. En la misma institución se realizaron entrevistas a la directora, la secretaria y varias docentes y se participó de diferentes eventos realizados por la escuela.

Por otro lado, en los dos movimientos de productores/as en los que realizamos trabajo de campo se crearon dos bachilleratos populares de adultos/as (ambos en la localidad de Abasto) bajo la modalidad del programa FinEs, en los cuales los alumnos provenientes de Bolivia superan el $80 \%$ de los asistentes. Uno funciona en el turno vespertino en el edificio de una escuela primaria y el otro funciona en la sede de una cooperativa de productores en turno mañana y vespertino. En dichos bachilleratos, tuvimos la posibilidad de asistir a la convocatoria de estudiantes al momento de su formación, y también de dar forma al proyecto pedagógico; es decir, participar como docentes y talleristas en diferentes actividades y estar presentes en múltiples instancias como observadoras. En uno de ellos se realizaron cinco entrevistas en profundidad a estudiantes productores/as de origen boliviano. En el otro se realizó un taller sobre trayectorias donde 15 estudiantes pudieron dar cuenta de su propia historia educativa, su asistencia a la escuela y las perspectivas a futuro para sí mismos/as y para sus hijos/as, así también sobre su historia migratoria y sus condiciones socioeconómicas.

Estas técnicas nos permitieron dar cuenta tanto de la categoría representaciones sociales como la de estrategias, lo que nos permitió dilucidar los diferentes sentidos construidos y las prácticas realizadas por los sujetos (productivas, culturales, económicas, sociales y educativas) cuya lógica estratégica se orienta hacia las metas educativas.

De campesino/a a horticultor/a. Trayectorias de las familias migrantes bolivianas hacia el periurbano platense

Los/as productores/as hortícolas del periurbano platense son los/as más importantes del país, tanto por su número (que hoy se estima en 5000 productores/ familias productoras) como por su nivel de capitalización (uso intensivo del paquete tecnológico del invernáculo) (García, 2014).

A partir del trabajo de campo realizado pudimos observar que las familias a las que pertenecen los/las sujetos/as aquí investigados/as viven en el mismo lugar en el que trabajan, es decir que la unidad doméstica y la unidad productiva se encuentran unidas. Esto dificulta la diferenciación del tiempo destinado a tareas productivas respecto del dedicado a las reproductivas. Las labores de la quinta son llevadas adelante por el grupo familiar (familia nuclear y ampliada). Los/as mayores se dividen el producción y reproducción del siguiente 
modo: el varón solo atiende la quinta; la mujer la quinta, la casa y las tareas de cuidado. A partir del trabajo de campo pudimos identificar que la mayoría de las actividades que se realizan en la esfera productiva son tareas compartidas entre ambos géneros. Las tareas de: carpir, sembrar-plantar-almacigar, hormonear, regar, atar, desbrotar, ventilar, cosechar, seleccionar, embalar, cargar y descargar, venta, mantenimiento y reparación del invernadero son realizadas por varones y mujeres. Mientras que preparar la tierra, curar y manejar el camión son tareas que en ocasiones efectúan ambos pero que generalmente son llevadas a cabo por el varón. En tanto que de encargar los insumos a las agronomías se ocupan las mujeres. Sin embargo, cuando nos adentramos en la esfera de trabajo reproductivo y de cuidado, ${ }^{7}$ la distribución de las tareas se vuelve más inequitativa. En este sentido, se pudo identificar que las tareas de reproducción y cuidado son llevadas a cabo por las mujeres: cocinar, limpiar, coser, lavar la ropa; preparar, llevar y traer a los/las niños/as a la escuela, ayudarles con las tareas, bañarles, cambiarles y llevarles al médico y cuidados de la salud en general, participar de reuniones de la escuela y de los momentos de recreación. Asimismo, realizar las compras de consumo cotidiano es un trabajo realizado por las mujeres y a veces por los varones; y comprar la ropa y alimentar a los animales son trabajos compartidos por ambos.

Los/as niños/as y jóvenes colaboran en las tareas domésticas y en las de la quinta, realizando algunas actividades en las cuales reproducen los roles de género desarrollados por los/as adultos/as. Es común que estas familias, llegado un determinado nivel de capitalización, contraten trabajadores/as asalariados/as por fuera del núcleo familiar (Insaurralde y Lemmi, 2018).

Las jornadas de trabajo son extensas y ocupan casi la totalidad de los días de la semana (solo se liberan el sábado después del mediodía); son de entre 9 y 10 horas diarias en la temporada invernal y de 12 a 15 en la temporada estival, momento en que se presenta el mayor trabajo. Las labores realizadas tanto bajo cubierta así como a campo abierto son extremadamente duras. Quienes las realizan soportan fríos, lluvias y heladas en invierno y sol directo y temperaturas que superan los 40 grados en el invernadero en verano.

Una de las características de este espacio productivo es que resulta dificultoso poder calcular a priori si la temporada dejará ganancias y en qué proporción lo hará. Los precios de las hortalizas son volátiles y lo recaudado debe poder asegurar la supervivencia del grupo familiar y el comienzo de un nuevo ciclo productivo. Esto depende de las especies que se hayan sembrado y su resistencia al clima y a las enfermedades propias de la producción bajo cubierta, y de la coyuntura macroeconómica. Estos factores definirán qué se terminará ofertando en el mercado (en cantidad y en variedad), y habilitarán la realización de ganancias considerables. Es importante aclarar que quienes perciben la mayor ganancia son los intermediarios en el proceso de comercialización y no en el/la productor/a directo/a, quien solo logra recuperar parte de ese plus si posee puestos de venta en los mercados minoristas o concentradores (Waisman, 2012; García, Le Gall y Mierez, 2011; Lemmi, 2015).

En el trabajo de campo pudimos observar que las condiciones de vida de los/ as sujetos bajo estudio son precarias, ya que para aquellos/as que no son dueños/as de las tierras no es rentable hacer mejoras en ellas, puesto que luego quedarán en manos del rentista. A raíz de esto, viven en las condiciones que proporcionan los/as dueños/as de la tierra: casillas de madera con techo de chapa, piso de tierra o alisado de cemento, baños (en su mayoría externos) con formato tipo letrina. No poseen agua corriente sino de pozo y utilizan
7. Según la bibliografía consultada, las tareas de reproducción son aquellas actividades que se realizan para permitir la subsistencia y la reproducción diaria de la vida. Las tareas de cuidado refieren a aquellas labores que tienen como objetivo atender las necesidades de los miembros dependientes de la unidad doméstica: niños, niñas, adultos mayores, enfermos o personas con discapacidad.

Sin embargo, también reciben cuidados miembros de la familia que no son vulnerables, como los varones adultos, quienes hacen uso del poder y de los privilegios que les otorga el sistema patriarcal que organiza la sociedad capitalista (Ginés, 2007; Franco Patiño, 2010; Calero, Dellavalle y Zanino, 2015). 
gas envasado en garrafa. Poseen heladera (en algunos casos, con frezzer), sin embargo, el acceso a las tecnologías de la información y la comunicación (TIC) es limitado. La preparación del alimento oscila entre la cocina con gas de garrafa y el fogón en el patio alimentado con la leña que se desecha de los invernaderos. Algunas familias complementan la producción hortícola con la cría de animales menores (mayoritariamente gallinas) para consumo propio. Según el nivel de capitalización, pueden poseer vehículo doméstico y/o de trabajo. Estas familias utilizan servicios de salud y educación públicos y suelen percibir diferentes subsidios estatales (Asignación Universal por Hijo, Salario Social Complementario, etc.). Asimismo, hay pocos espacios de esparcimiento en las cercanías de las quintas, sobre todo en la localidad de Abasto, y las plazas y centros comerciales se encuentran alejados, a la vez que el servicio público de transporte es deficitario (Attademo, 2008; Lemmi, 2015).

A pesar de todas las carencias en las condiciones de vida -que han llevado a investigadores a caracterizar a estas familias como socialmente vulnerables (Filgueira, 2001)-, la horticultura les ha posibilitado la mejora y el ascenso social. En efecto, muchos han pasado de peones a medieros y luego a arrendatarios, aunque ninguno ha alcanzado una posición tal que le permita ser dueño de su porción de tierra (Benencia et al., 2009; Garatte, 2016; Merchán, 2016).

Para las familias de origen boliviano, el proyecto migratorio hacia la horticultura platense es una apuesta a la posibilidad de mejora y ascenso social. Aun en las duras y, en ocasiones, adversas condiciones laborales, migrar a la ciudad de La Plata implica para ellos migrar "al progreso", entendido este como posibilidad de acceso a mercancías, educación y ofertas lúdicas y culturales (Salazar de la Torre, 2008; Castro, 2016).

En el territorio periurbano hortícola platense encontramos una oferta educativa pública escasa en los niveles iniciales y primario, pero suficiente en el nivel secundario aunque nula en nivel terciario y universitario. Las escuelas allí ubicadas tienden a tener un alto porcentaje de estudiantes de origen boliviano $\mathrm{o}$ argentinos/as provenientes de familias con dicha historia migratoria. Este porcentaje varía según las escuelas estén más cerca o más lejos de los perímetros de la ciudad habitada en mayor medida por argentinos/as y en menor medida por familias migrantes.

\section{Una segunda oportunidad: adultos/as transitando la escuela primaria y secundaria}

Los/as adultos/as que deciden retomar sus estudios secundarios en las escuelas de Abasto debieron interrumpir su escolaridad en la infancia o juventud. En sus relatos, ellos y ellas dan cuenta de la lejanía de la escuela de sus hogares en Bolivia, lo que dificultaba que asistieran a clases. Así como la conformación de hogares con muchos hijos e hijas que hacía más difícil la reproducción de la familia con la porción de tierra que poseía, debiendo salir a trabajar o quedarse al cuidado de hermanos/as menores y/o animales de granja. Esto nos permite situar a las experiencias de los/as adultos/as en una misma trayectoria de clase, en que la posibilidad de mantener una continuidad escolar en su pasado estuvo en gran parte obstaculizada y condicionada por la pertenencia a un estrato social bajo. En estos casos, las trayectorias escolares y laborales se presentaron como excluyentes en un momento de la biografía de estos actores, y la única opción posible era dejar los estudios para trabajar. Sumado a esto, la falta de una oferta escolar accesible, en relación con su ubicación geográfica y los 
regímenes de asistencia de los establecimientos, fue un factor que contribuyó con la necesidad de tomar esta decisión.

En los casos de algunas mujeres, pudimos identificar problemáticas que son propias de serlo en una sociedad desigual en relación con el género y la influencia que esto tiene en sus trayectorias escolares. Las mujeres mayores a cargo del hogar (ya fueran madres o madrastras) y también los varones (padres o padrastros) impidieron o dificultaron el paso de las hijas por el sistema educativo en tanto entendían que su rol se desempeñaba dentro de la casa, cumpliendo las tareas domésticas y de maternidad.

\begin{abstract}
A mí no me dejaron estudiar, me decían que las mujeres se tenían que quedar en la casa a cuidar a los hijos, al marido, a limpiar y que para qué iba a ir a la escuela si lo importante era saber hacer las cosas de la casa.
\end{abstract}

porque una vez que tenés marido ya no estudias. Ellos siguen pensando lo mismo, dice 'ahora que tiene marido, ahora quiere estudiar' (Risas).

Mi mamá, ella no sabía leer pero ella quería que sus hijos estudien. Mi papá no. A mí me sacó a los dos o tres año mi papá.

Dejé la escuela. Dejé la escuela, en realidad yo quería ir. Quería seguir yendo. Pero después mi papá ya... bah, mi padrastro... no, no quería que yo vaya, eh... porque... yo era muy rebelde. Pero... qué sé yo, yo a veces no quería... no quería estar en la quinta... Y bueno, entonces, eh... mi papá se enojó, ya después no quería mandarme a la escuela... Y después yo me escapaba y me iba a la escuela igual [ríe]...

“Mi mamá falleció, cuando tenía tres años... Y tuve madrastra. Y mi madrastra era medio mala... Entonces com... cuando se juntó con mi madrastra, que no sabe leer, entonces dijo que las mujeres cuando estudian hacen sufrir al hombre, dijo ella (...) Que las mujeres no deben estudiar, me decía... (Cinco de las 36 mujeres entrevistadas durante el trabajo de campo)

Sin embargo, estas mujeres en la actualidad encontraron nuevos sentidos que las hicieron superar los mandatos de género devenidos de sus entramados familiares.

Si bien el deseo de continuar la escuela tuvo, tanto en varones como en las mujeres, una presencia permanente en sus vidas, este siempre era postergado por las limitaciones propias de largas jornadas laborales que implica la horticultura y a su vez, por la falta de una oferta educativa acorde con sus necesidades. Así, el lugar que comienza a ganar la educación de adultos/as en términos de políticas educativas a partir del año 2006 en Argentina, y la puesta en marcha de un plan orientado específicamente a la finalización de estudios primarios y secundarios de adultos/as, con una fuerte inserción en los barrios periféricos y con un régimen de asistencia y horarios accesibles, forma parte de un contexto que posibilitó su reinserción escolar. Para asistir a la escuela, los y las horticultoras realizan grandes esfuerzos,

que implica ausentarse de la quinta y redoblar la carga de trabajo al día siguiente, así como buscar maneras de dejar a los y las hijas al cuidado de otras personas. También deben superar sus propios miedos y "vergüenzas", devenidas de un sistema educativo que ha construido una trayectoria teórica como estandarización y norma de todas las trayectorias educativas posibles y 
que sanciona en forma negativa cualquier modificación a ese recorrido "ideal" valorado positivamente (Terigi, 2009).

Los sentidos que agencian a los y las horticultoras al momento de retomar sus estudios son varios. Por un lado, manifiestan querer "escribir bien, "sin faltas de ortografia", "sin palabras de más, con los puntos donde van". También desean "hablar bien", "expresarme", "leer de corrido", "perder el miedo", "defenderme mejor", "aprender cosas nuevas", "tener una firma que no sea mi nombre y apellido".

Entendemos que el deseo de mejorar su lectoescritura así como la expresión oral se asocia a lo que Salazar de la Torre concluyó respecto de la significación que adquiere la educación formal para la población boliviana de origen campesino. En dicho sentido, la escolarización y el contacto con la lengua española les permitiría cumplimentar su deseo de diferenciarse y alejarse de su condición étnica quechua, aymara o guaraní (Salazar de la Torre, 2008).

La finalización de los estudios secundarios aparece también, al igual que para con sus hijos/as, ligada a la posibilidad de acceder a la universidad y de estudiar una carrera profesional como vía para poder acceder a un "mejor trabajo". Así, la continuidad de sus trayectorias escolares se presenta, en primera instancia, como una apuesta a largo plazo, vinculada con el interés por modificar sus trayectorias laborales a partir de la acreditación de estudios. Pero también expresan sus deseos de continuar sus estudios secundarios para, una vez concluidos, tener una opción laboral alternativa,

Yo volví para terminar la secundaria... para seguir estudiando para aprender muchas cosas de la escuela, para saber más. Quiero tener un trabajo en el futuro... Conocer, aprender, saber expresarte mejor yno tener miedo... Y... me gustaría seguir estudiando, como ser, en enfermería.

Yo vengo a la escuela para aprender un poco más, sé muy poco. Para después hacer algún curso de algo como ser mecánica o electricidad.

Vengo a la escuela porque quiero aprender más cosas para trabajar y continuar a mucho más poder. Llegar en algún cargo para poder trabajar, como ser, quiero ser una doctora.

También aparecen otros relatos en los que manifiestan querer seguir trabajando en la horticultura pero pudiendo tener una alternativa en los momentos cíclicos propios de esta producción: "poder hacer cursos", "cuando la quinta no va bien", "cuando no hay trabajo", "cuando la verdura no se vende bien", "para poder hacer changas".

En algunos casos, los hijos e hijas aparecen en el centro de la escena, ya que algunas madres quisieran seguir estudiando para ayudarles al momento de "la tarea". Sienten preocupación en tanto sostienen que su nivel educativo no es lo suficientemente "bueno" como para poder orientarles en el seguimiento de los deberes escolares. El temor a no comprender las consignas que puedan dar maestros/as y profesores/as y no conocer los temas que los niños/as y jóvenes/as deben estudiar es una fuente de preocupación y angustia para ellas.

Vengo a la escuela para aprender para poder expresarme bien y poder ayudar a mis hijos. 
Bueno a mí me gustaría seguir el estudio para también expresarme y también tener compañerismo, saber leer y sumar. Y también poder enseñar a mis hijos y me gusta que mis hijos se alegren verme hacer la tarea y eso a mí me anima más.

Me gusta aprender en la escuela para defenderse y entender mejor y para ayudar a nuestros hijos.

$\mathrm{Al}$ indagar en profundidad acerca de los sentidos que los/as conducen a continuar la escuela nos encontramos también con cuestiones que refieren a su experiencia en el presente. Observamos que la continuación de la permanencia en la escuela aparece así motivada no solo por objetivos futuros sino también por lo que los sujetos experimentan al asistir a la escuela, como un espacio de sociabilidad que habilita nuevos aprendizajes ligados a la relación con los/as otros/as, como un lugar de distracción, de nuevos desafíos, de superación de estigmas ajenos y limitaciones propias.

Sí porque a veces, este... nos encontramos con los compañeros, nos reímos... sí me gusta. Porque a veces uno está triste en la casa y va y como que te despeja un poco. Te olvidás de los problemas.

Yo vengo a la escuela para poder manejarme sola, porque siempre necesité de alguien para hacer un trámite y para poder aprender y escribir y para poder hacer amistades.

Y... mi papá dijo no... de allá como muy de atrás escuché que 'no, ¿qué va a ir? si no se calentó hasta ahora que va, no va a ir ahora', dijo. Y bueno entonces después eh... demostré que no. Demostré que sí voy a poder, y que sí voy a seguir yendo.

\section{Para saldar deudas familiares: jóvenes que transitan la escue- la secundaria}

Cuando repasamos la historia migratoria de las familias a las que pertenecen los/las jóvenes y adultos /as horticultoras abordados aquí, vemos cómo en su temporalidad están contemplados los tiempos del calendario escolar y la posibilidad de inscribir a las jóvenes generaciones en la escuela más cercana.

...nos vinimos acá y ya nos quedamos acá... nos queda más cerca aquí la escuela, todo... igual las traía, ¿eh?... eso que cuando nos vinimos no encontrábamos lugar...no encontrábamos y hasta fuimos a pedir a la escuela privada y eso que no teníamos, no sabíamos si íbamos a poder pagar, pero por lo menos... y bueno, al final encontramos acá, y ahí quedaron...

para nosotros es muy importante que vayan a la escuela... mirá que la anoté hace años ya hizo. Porque viste que ella por la edad, yo la anoté a los 3 años pero no me la recibieron, ya había muchos chicos acá... otros hijos de quinteros también... Después entró de 4 a 5, después 5, 6. Claro, ahora se redisputan las bancas acá. Porque van muchos, ahora hay chicos que ni entran siquiera... No, y me dijeron que el año pasado se armó...

...vivimos en Mar del Plata, hacíamos a campo, pero era duro, hacía frío, viento. Nos vinimos para La Plata, nos gustó acá [Etcheverry], había escuela, enseguida la anotamos para que empezara con todos sus compañeros, que no se atrase. 
Porque cuando vinimos solo había Jardín me parece que y el primario, pero el secundario no. Secundario no, no estaba nada. Era todo así, qué sé yo, había campo. Sí, yo vi que en el 2005 dice que hicieron todas las instalaciones me parece. Y después porque ya los que salían de acá tenían que irse a Olmos. Porque acá es impresionante la cantidad de chicos que hay ahora sí, sí, sí tuvieron que abrir estos años, el año pasado no....

Así también es el grupo familiar el que acompaña en su conjunto el proyecto migratorio, siendo las jóvenes generaciones las que asumen como propio el deseo de sus padres de mejora de las condiciones de vida y encaran sus estudios desde ese lugar, aun cuando esto es fuente de disputas y conflictos. Los/ las jóvenes ponen su propia voz a este proyecto de los/las adultos/as del hogar,

No quiero seguir en la quinta, porque no me gusta y esa no es la vida que yo quiero tener, una vez que haya terminado la escuela pienso seguir estudiando o en una universidad o en un instituto, después de todo eso es lo que quieren mis padres y yo también.

No lo sé, si Dios me ayuda tal vez ya no sea quintero.

Para seguir adelante, estudiar, seguir una carrera y seguir estudiando.

Porque mis papás quieren que estudie algo y que no me quede en la quinta... es muy costoso... yo quisiera ser ingeniero agrónomo.

Quiero seguir estudiando para policía.

Me gustaría seguir y estudiar para enfermería... y para ser alguien y tener un trabajo ideal.

Los padres y madres de estos jóvenes no lograron completar sus estudios primarios, y debieron interrumpir su escolaridad por motivos laborales ya que se encontraban comprometidos en la reproducción económica de la familia. De origen campesino, al momento de verse afectada la reproducción familiar dejaban la escuela para ayudar a sus padres en la chacra o emplearse en la ciudad como albañiles, empleadas domésticas o de comercio, niñeras, costureras, entre otros; o migrar a la Argentina a trabajar en la zafra y el tabaco.

Estos relatos dan cuenta de situaciones que ponen en tensión los resultados de otras investigaciones que indicaban que para las familias de los sectores populares era importante el tránsito de sus hijos/as por la escuela primaria, no así por la escuela secundaria (Sistema de Información de Tendencias Educativas en América Latina - SITEAL, 2009; Binstock y Cerrutti, 2012; Briscioli, 2013). En los casos aquí estudiados, el hecho de que sus hijos e hijas puedan acceder a la educación pública con perspectiva de continuar los estudios hacia niveles superiores es un anhelo sentido que los reivindica en su posición de padres y les da sentido a su realidades de migrantes horticultores. Esto es especialmente fuerte en el relato de las madres, en quienes es muy difícil percibir un proyecto propio que no contemple a sus hijos/as y su bienestar como sentido de su existencia: “... yo me quería ir de la casa... no estaba bien, pero pensé en ellos [refiriéndose a sus hijos]... como ya terminaban las clases y bueno, no los iba a cambiar de escuela... y no quiero que pierdan la escuela... y me quedé por mis hijos..."

En este sentido, podemos observar cómo la familia construye día a día, en su hacer cotidiano, el deseo de mejora social facilitando con acciones concretas el 
paso de sus hijas/os por la escuela. Los/as jóvenes entrevistados/as contaron en sus relatos que trabajan en la quinta con sus padres entre 2 y 4 horas diarias a contraturno de la escuela y medio sábado los fines de semana o domingos cuando es tiempo de carga. Sin embargo, priorizan los momentos de estudio para que los tiempos de trabajo no compitan con los tiempos de estudio, fomentando así que en momentos de exámenes los/as jóvenes se puedan concentrar en las tareas que esto les requiera.

...a veces paso y miro... si está estudiando no la hago venir a la quinta... ahora si está con el celular, ahí sí me la traigo...

...no, no, cuando tiene examen a la quinta no... porque yo quiero que estudie... no quiero que me repita... yo confiaba en ella y la dejé libre y no la controlé, no estuve atrás de ella siguiéndola. Me mintió en que iba bien, que estaba aprobando todo y cuando llegó fin de año había desaprobado más materias y terminó repitiendo.

Por otro lado, las madres - quienes se encargan de las tareas de cuidado, dedican tiempo y esfuerzo en realizar seguimientos diarios de los quehaceres escolares- se sientan junto a sus hijos/as e intentan ayudar en la resolución de las tareas. Conversan con ellos/as de lo aprendido en la escuela, lo que también es para ellas una fuente de conocimiento, dado que, como señalamos, solo alcanzaron los estudios primarios. En este sentido, los/as hijos/as se convierten en mediadores del saber que circula en la institución escolar y es transmitido por ellos/as a los padres y madres en el hogar. En virtud de ello, la escolaridad es un hito importante, no solo en la biografía de los/as jóvenes, sino de todo el núcleo familiar.

Es importante que esté limpio el cuaderno. Eso lleva notas en Bolivia. En serio, tiene notas la carpeta tiene que estar... prolijito. A mi hijo preguntale como todos los días ¿por qué esta esa manchita? Le tengo así todo el tiempo, pero me gusta que este así en orden, bien ordenadito.

Yo se ahorita más de la Argentina que de Bolivia porque yo sé qué día todo, yo me lo aprendí solo por ser mamá. Lo que te digo que en las matemáticas es otra cosa, diferente enseñan, el mismo resultado te da pero de otra forma y ahí me marean a mí también. Yo cuando con los chicos a veces hago y no sabía eso.

Con mis hijas a veces me traían y no entendía, pero ahora, por similar, algunos que ya me dieron ya entiendo. Porque tienen libros y yo he mirado y ahora más o menos le entiendo como es. Con paréntesis, esos que van así aquí....

En lo que respecta a las demandas y exigencias de las familias a las instituciones educativas, a diferencia de otros casos estudiados, en los que estas reclaman al cuerpo docente mayor disciplina (Gavazzo et al., 2014; Diez, 2014), en la institución a la cual asisten los/as jóvenes aquí estudiados no se registran episodios de violencia o indisciplina. En estos casos, el reclamo de los padres y madres hacia los docentes de la institución radica en el alto nivel de ausentismo de estos/as y en la merma del nivel académico que ello conlleva. Sostienen que para que sus hijos/as continúen en los estudios superiores requieren de ciertos saberes que, de no brindarlos la escuela secundaria, hará más lento y dificultoso el paso por la universidad. Esta crítica que se asoma en el relato de las madres hacia el ausentismo de los/as docentes no fue destacada en entrevistas realizadas a directivos de la Escuela como fuente de conflicto intraescolar. 
Es que también faltan mucho, eh, los profesores... Sí, faltan un montón. Porque la semana pasada, a veces que tienen qué sé yo, salen a las ... Bueno, la más grande no, casi no. El de la más chica falta mucho. Hay un profesor me acuerdo que falta mucho.

el bachillerato en Bolivia es mejor y después cuando entran a la universidad les va bien, no abandonan... los bolivianos que vienen a estudiar a la universidad les va mejor que a los nuestros que estudian en las escuelas acá [refiriéndose a las escuelas de la zona periurbana] tienen un mal nivel educativo y después a los chicos les va mal en la universidad.

Si bien se han detectado casos de discriminación, tal como sostienen otras investigaciones (Diez, 2014), el hecho de que en las escuelas aquí estudiadas el porcentaje de estudiantes con historia familiar de migración sea muy alto crea una comunidad de pares que ampara y genera barreras a dichos ataques. En este sentido, no se encuentra en la institución un ambiente hostil, que dificulte o ralentice el proyecto familiar de que los/as jóvenes accedan a las credenciales educativas. Cuando se pregunta a los padres por este anhelo, ellos/as declaran querer que sus hijos/as "sean alguien", "que aprendan a hablar bien" (haciendo alusión al diálogo fluido y con vocabulario "adecuado"), "no pasen lo que yo pasé", "que no tengan que trabajar en la quinta", "que estén mejor" y entienden que el estudio les habilitará "trabajos mejores", "que paguen más que la verdura", "que no sean tan sacrificados".

\section{"Ser alguien en la vida". Acerca del sentido de la educación en jóvenes y adultos/as horticultores/as}

Encontramos así que la significación construida en torno a la educación ocupa un lugar muy importante en las vidas de los sujetos aquí estudiados. Al igual que Cerletti y Santillán, que han analizado otras fracciones de los sectores populares, observamos que la escolarización de las jóvenes generaciones es activamente construida en las acciones de la cotidianidad y a su vez está fuertemente naturalizada como una fase ineludible de la vida (Santillán, 2009; Cerletti, 2010). Tal como ellas demostraron, los sujetos aquí analizados producen innumerables prácticas cotidianas asociadas a su escolarización. Esto se ve reflejado en dos sentidos: por un lado, en relación con los/as adultos/as, en su decisión de retomar y en sus esfuerzos por completar sus trayectorias escolares aun en la adultez; por otro lado, en el carácter insoslayable que adquiere la educación de los hijos/as en el planeamiento familiar.

Para las madres de los/as jóvenes que fueron entrevistadas en este estudio, como para los/las adultos/as que asisten a los bachilleratos en formato FinEs ya mencionados que provienen de familias hortícolas, la quinta se convierte en un fin en sí mismo; esto implica la posibilidad de salir de Bolivia, de alcanzar bienes a los que de otra forma no podrían acceder y es la posibilidad de "darles un futuro" a sus hijos/as.

El futuro es visto como la posibilidad de tener "un título universitario", un "trabajo mejor" y, en ese sentido, la educación se transforma en una de las estrategias familiares de vida más sentidas $y$, por ende, sostenida con más fuerza. Es por ello que entre las pocas demandas que les realizan a la institución educativa se encuentra el reclamo hacia la asistencia de los docentes, para que el ausentismo no implique una merma en el nivel educativo esperado. 
Para los/as hijos/as, la quinta se vuelve el medio con el que van a alcanzar esa vida mejor tan anhelada y la educación se convierte en una estrategia también valorada y sostenida como propia, que a su vez se encuentra dentro de un proceso propio de búsqueda de autonomía (Cicchelli, 2001). En este sentido, es tan importante la implicación y supervisión de los padres y madres en el trabajo escolar diario, así como las propias actitudes y autocontrol de los jóvenes para tomar decisiones acerca de su futuro (Labrador Fernández y Blanco Puga, 2007). Gago y Maggi observaron una situación similar en los casos de migrantes bolivianos en las ciudades de Comodoro Rivadavia y Córdoba, y dieron cuenta allí también que el proyecto migratorio incluye el compromiso de toda la familia aunque ello no se traduzca finalmente en trayectorias educativas exitosas (Gago y Maggi, 2008).

En relación con los casos analizados en el presente trabajo, podemos afirmar la íntima relación que presentan las trayectorias escolares de los sujetos, no solo con el contexto en el que se insertan y en las oportunidades que en este sentido se les presentan, sino también con los sentidos que construyen y las estrategias que agencian en su interés por asistir y finalizar la escuela. Identificamos el sentido que le otorgan a la educación como condición necesaria en la incidencia de sus trayectorias laborales, al abrir oportunidad a nuevas opciones, al "ser alguien" vinculado a la idea de "tener un mejor trabajo", "tener una profesión" y a la superación de la historia pater/materna. Tal como sostiene Salazar de la Torre al estudiar el sentido que le otorga a la escolaridad la población campesina en Bolivia, la escuela representa la posibilidad de incorporarse a la "civilización", la desmarcación tanto de su origen étnico como del atraso que le atribuyen a su condición de habitantes del campo (Salazar de la Torre, 2008).

También hemos observado aquí sentidos relacionados con la escuela como espacio de socialización, como vía para generar lazos, amistades, momentos de distensión, de formación, de participación. Sentidos que, lejos de lo formal, inciden en la vida cotidiana de estos sujetos, y que aportan a enriquecer sus prácticas diarias, al romper con la dinámica más individualista y solitaria que ocupa el trabajo como única actividad central. Como sostiene Pascual (2010):

el lugar que lo educativo y lo escolar tenga en la vida de las personas se torna inteligible al interior del proceso de reproducción social del sujeto y de su grupo de referencia y siempre en diálogo con las características histórico-sociales de la formación social. Así, el lugar y la significatividad de lo educativo no se mantienen inmutables en la vida de las personas. A lo largo del curso de la vida, las experiencias laborales, migratorias, familiares - por solo citar algunas- se van imbricando e influyendo en las modificaciones de la valoración de la educación y la escolarización en diferentes momentos vitales. (Pascual, 2010, p. 17)

Por otra parte, los casos aquí abordados se distancian de los resultados de otras investigaciones. En primer lugar, Kraser y Ockier, en la localidad de General Daniel Cerri, observaron que en las familias migrantes bolivianas las trayectorias socioproductivas aparecen incidiendo negativamente en la escolarización, ya que los padres deciden que sus hijos dejen de ir a la escuela para dedicarse a las labores productivas. Las condiciones de precariedad en las que viven estas familias impiden, a diferencia de los casos aquí estudiados, la plena escolarización de las jóvenes generaciones en tanto sus estrategias familiares de vida ponen en primer lugar superar la situación de pobreza en la que se encuentran y la escolarización aparece como un objetivo más a futuro (Kraser y Ockier, 2008). 
Así también, Gavazzo, Beheran y Novaro sostuvieron que los jóvenes migrantes bolivianos en algunos casos debieron abandonar sus estudios para privilegiar el trabajo forzados por las decisiones de los/as adultos/as del hogar. A su vez, han señalado que la condición social y las marcaciones étnicas tienden a influir negativamente en las trayectorias escolares (Gavazzo et al., 2014). Sin embargo, en los casos de jóvenes y adultos/as migrantes dedicados/as a la horticultura en el periurbano platense aquí estudiados, poseen trayectorias escolares de permanencia en el sistema educativo.

Asimismo, a partir de lo analizado, podemos sostener que la escolaridad es un hito importante en la biografía de los/as alumnos/as migrantes bolivianos/ as investigados/as aquí, tal como sostienen Gavazzo et al. (2014). Agregamos a ello que en estos casos, la educación se convierte en un hito, no solo en la biografía de los/as jóvenes y adultos/as, sino de todo el núcleo familiar.

\section{Reflexiones finales}

En este trabajo reconstruimos los sentidos que los/las jóvenes y adultos /as integrantes de familias productoras de hortalizas del Gran La Plata construyen en torno a la educación. Asimismo, analizamos las estrategias que estos/as ponen en juego en función de dichos sentidos para cumplimentar la escolarización.

Tal como señalamos en el inicio, un conjunto de investigaciones revalorizaron el significado que adquiere la escolarización para los sectores populares. Abonando a dichos planteos, en el caso aquí estudiado pudimos observar el significado altamente positivo que dan los/las jóvenes y adultos /as integrantes de familias horticultoras al pasaje por la escuela y a la obtención de credenciales educativas. Asimismo, y reforzando las hipótesis y análisis de las investigaciones pioneras ya nombradas, identificamos aquí también las estrategias que realizan los/las jóvenes y adultos/as para avanzar en su escolarización. Pudimos reconstruir cómo estas familias campesinas que vivían en Bolivia proyectaron la migración a la Argentina como parte de sus anhelos de búsqueda de una vida mejor. Esta migración se realizó al área de la horticultura platense, territorio productivo que permite el cumplimiento de ese objetivo de mejora social. Del mismo modo, las condiciones que impone la estructura productiva son fuente tanto de los recursos económicos necesarios para la reproducción del núcleo familiar y sostenimiento de la escolaridad de los adultos/as y miembros más jóvenes, pero también el motivo para desplegar estrategias que les habiliten un futuro mejor. Para los/as adultos/as de estas familias, la migración al perirubano hortícola platense implica una mejora social en tanto les posibilita la obtención de bienes y servicios que, aun siendo deficitarios, no podrían alcanzar en su lugar de origen. Uno de ellos, quizás el más importante, es la posibilidad que, según los sentidos construidos por los/las sujetos/as en cuestión, habilita la educación pública en la Argentina de obtener titulaciones de nivel medio y superior que redundan en un futuro en mejores condiciones laborales y de vida.

Es así que despliegan estrategias en favor del acceso de sus hijos/as a los estudios primarios y secundarios acompañando y facilitando esa trayectoria de múltiples maneras. También, los/las adultos/as deciden retomar sus estudios para alcanzar credenciales educativas que les permitan acceder a mejores ofertas laborales con el fin de que se traduzcan en una mejoría en sus condiciones de existencia y la del núcleo familiar de conjunto. Los sentidos construidos por los/las jóvenes y adultos /as sobre la migración, la horticultura y la educación 
se convierten en los pilares sobre los que los/as sujetos aquí estudiados/as desplegarán un conjunto de estrategias que se espera ayuden a la mejora de su calidad de vida. Una vez más, pudo observarse cómo los sectores populares obran de maneras concretas para romper el círculo de la reproducción social.

\section{Financiamiento}

Este trabajo fue financiado con aportes del CONICET y de la UNLP a través del proyecto I+D "Reconfiguraciones en el espacio rural bonaerense: estrategias familiares de reproducción social, trayectorias laborales y educativas y procesos de sociabilidad en el periurbano platense, Necochea y Junín".

\section{Agradecimientos}

Agradecemos al CONICET, a la UNLP, UNQ y UNAJ por habernos brindado los instrumentos necesarios para el desarrollo de la presente investigación. A los y las jóvenes y adultos/as productoras de hortalizas del Gran La Plata por habernos abierto las puertas de sus quintas y compartido con nosotras sus historias vitales. Por último, a las instituciones educativas por la confianza e información brindada. Esperamos esta investigación sea de su utilidad. 


\section{Q Referencias bibliográficas}

"Attademo, S. (2008). Lazos sociales y estrategias: ¿una opción para las familias hortícolas empobrecidas? Mundo Agrario, 17. Batallán, G. y García, J. F. (1992). Antropología y participación, contribución al debate metodológico. Publicar en Antropología y Ciencias Sociales, en Revista Publicar en Antropología y CienciasSociales, año 1, núm. 1, pp. 79-93, Buenos Aires.

» Benencia, R., Quaranta, G. y Souza Casadinho, J. (Coords.). (2009). Cinturón hortícola de la Ciudad de Buenos Aires. Cambios sociales y productivos. Buenos Aires: CICCUS.

» Benencia, R., Ramos, D. y Salusso, F. (2016). Inserción de horticultores bolivianos en Río Cuarto. Procesos de inmigración, trabajo y conformación de economías étnicas. Mundo Agrario, 17 (36).

»Binstock, G. y Cerruti, M. (2012). Los estudiantes inmigrantes en la escuela secundaria. Integración y desafíos. Buenos Aires, Fondo de las Naciones Unidas para la Infancia (Unicef).

》 Bourdieu, P. (1988). La distinción. Buenos Aires: Taurus.

»Bourdieu P. (1990). Sociología y cultura. México D.F.: Grijalbo.

》 Bourdieu P. (1991). El sentido práctico. Madrid: Taurus.

»Briscioli, B. (2013), Tendencias y puntos críticos en las trayectorias escolares de estudiantes de Escuelas de Reingreso de la Ciudad de Buenos Aires. Una indagación sobre las condiciones de escolarización en la construcción de las trayectorias escolares (tesis de doctorado). Doctorado en Educación. Facultad de Ciencias de la Educación. Universidad Nacional de Entre Ríos.

"Calero, A., Dellavalle, R. y Zanino, C. (2015). Uso del tiempo y economía del cuidado. Documento de Trabajo nro. 9. Secretaría de Política Económica y Planificación del Desarrollo. Ministerio de Hacienda. República Argentina.

"Castro, A. (2016). Saberes migrantes. Trayectorias de productores bolivianos del periurbano platense (tesis de grado). Universidad Nacional de La Plata. Facultad de Humanidades y Ciencias de la Educación. La Plata.

»Cerletti, L. B. (2010). Familias y escuelas: aportes de una investigación etnográfica a la problematización de supuestos en torno a las condiciones de escolarización infantil y la categoría 'familia'. Intersecciones en Antropología, 11, 185-198.

»Cerletti, L. B. (2014). Familias y escuelas. Tramas de una relación compleja. Buenos Aires: Biblos.

»Cicchelli, V. (2001). Les jeunes adultes comme objet théorique. Recherches et prévisions, 65(1), 5-18.

»Diez, M. L. (2014). Procesos de identificación, migración y escolaridad en el sur de la Ciudad de Buenos Aires. Una aproximación desde la dimensión generacional. AAVV, XI Congreso Argentino de Antropología Social. Rosario: Congreso Argentino de Antropología Social.

" Filgueira, C. (2001). Estructura de oportunidades y vulnerabilidad social: aproximaciones conceptuales recientes. En AAVV, Seminario Internacional “Las Diferentes Expresiones de la Vulnerabilidad Social". Santiago de Chile, Chile. 
»Franco, S. (2010). La alimentación familiar una expresión del cuidado no remunerado. Prácticas de oficio, 6, 1-8.

» Gago, M. A. y Maggi, M. F. (2018). Trayectorias socio-educativas de jóvenes migrantes en Córdoba y Comodoro Rivadavia (Argentina). XII Reunión de Antropología del Mercosur “Experiencias etnográficas, desafíos y acciones para el siglo 21", t. I. Posadas: Facultad de Humanidades y Ciencias Sociales, Universidad Nacional de Misiones. https://ram2017. com.ar/?p=2144

» Garatte, M.C. (2016). Entre la quinta, la escuela y la ciudad. Trayectorias laborales de jóvenes en el cinturón hortícola de La Plata (2003-2015) (tesis de grado). Universidad Nacional de La Plata. Facultad de Humanidades y Ciencias de la Educación. En Memoria Académica. Recuperado de_http://www.memoria.fahce.unlp.edu.ar/tesis/te.1243/te.1243.pdf

»García, M. (2012). Análisis de las transformaciones de la estructura agraria hortícola platense en los últimos 20 años. El rol de los horticultores bolivianos (tesis de doctorado). Universidad Nacional de La Plata. La Plata.

» García, M. (2014). Fuerza de trabajo en la horticultura de La Plata (Buenos Aires, Argentina): Razones y consecuencias de su competitividad. Trabajo y sociedad, 22, 67-85.

» García, M., Le Gall, J. y Mierez, L. (2011). Comercialización tradicional de hortalizas de la Región Metropolitana Bonaerense. Herencias, dinámicas e innovaciones de un sistema complejo. Boletín Hortícola, (47),8-15.

» Gavazzo, N., Beheran, M. y Novaro, G. (2014). La escolaridad como hito en las biografías de los hijos de bolivianos en Buenos Aires. Revista Interdisciplinar da Mobilidade Humana, 22 (42),189-212.

» Giménez Montiel, G. (2005). La concepción simbólica de la cultura. En Teoría y análisis de la cultura. México: Instituto Coahuilense de Cultura. Ginés, M. E. (2007). División sexual del trabajo. En S. B. Gamba (Coord.). Diccionario de estudios de género y feminismos. Buenos Aires: Biblos, 99-102.

» Guber, R. (2001). La etnografía: método, campo y reflexividad. Buenos Aires, Argentina: Norma.

»Insaurralde, N. y Lemmi, S. (2018). Cuerpos Productivos, cuerpos reproductivos. El caso de las mujeres productoras de hortalizas del Gran La Plata (2017). En AAVV V Jornadas CINIG de Estudios de Género y Feminismos. III Congreso Internacional de Identidades, "Desarmar las violencias, crear las resistencias". La Plata, Argentina: Facultad de Humanidades y Ciencias de la Educación. http://jornadascinig.fahce.unlp.edu.ar/actas-publicadas

» Jodelet, D. (1989). Les représentations sociales. Paris: Presses universitaires de France.

» Kraser, M. B. y Ockier, C. (2008). La dimensión educativa en los niños de familias bolivianas de la localidad de General Daniel Cerri. Boletín Geográfico, 31, 229-244.

» Labrador Fernández, J. y Blanco Puga, M. (2007). Trayectorias educativas y laborales de los jóvenes hijos de inmigrantes en España. Migraciones, 22, 79-112.

» Lemmi, S. (2015). Condiciones de vida, conflicto y conciencia de clase en los horticultores del Gran La Plata, 1940-2003. Living conditions, conflict and class consciousness of horticulturists from Gran La Plata, 1940-2003. Izquierdas, (25).

» Levinson, Bradley y Holland, Dorothy (1996). “La producción cultural de la persona educada: una introducción”. En: Bradley Levinson, Douglas Foley y Dorothy Holland (eds.). The cultural production of the educated person. Critical ethnographies of schooling and local practice. State University of New York, New York. 
» Merchán, A. G. (2016). Valorización de la tierra en el Cinturón Hortícola Platense. Disparidad en el valor de los arrendamientos (tesis de maestría). Magíster en Economía Agroalimentaria. Facultad de Ciencias Agrarias y Forestales. Universidad Nacional de La Plata.

"Nelson, I. A. (2010). From quantitative to qualitative: Adapting the life history calendar method. Field Methods, 22(4), 413-428.

" Pascual, L. (Coord.) (2010). Trayectorias socio-educativas de jóvenes y adultos y sus experiencias con la escuela media. Buenos Aires, Argentina: DiNIECE.

»Ringuelet, R. (comp.) (2000). Espacio tecnológico, población y reproducción social en el sector hortícola de La Plata. La Plata, Argentina: Facultad de Humanidades y Ciencias de la Educación.

" Ringuelet, R. (2009). La complejidad de un campo social periurbano centrado en la zonas rurales de La Plata. Mundo Agrario, 9(17). Recuperado de https://www.mundoagrario.unlp.edu.ar/article/view/vogn17ao7

》 Rockwell, E. (2009). La experiencia etnográfica. Historia y cultura en los procesos educativos. Buenos Aires: Paidós.

"Salazar de la Torre, C. (2008). Ser alguien, ser boliviano. Niños, adolescentes y jóvenes en el umbral de la ciudadanía. Cuaderno de Futuro, 24.

》Santillán, L. (2009). La crianza y educación infantil como cuestión social, política y cotidiana: una etnografía en barrios populares del Gran Buenos Aires. Anthropologica, 27, 47-73.

»Santillán, L. (2012). Quiénes educan a los chicos. Infancia, trayectorias educativas y desigualdad. Buenos Aires: Biblos.

» Sistema de Información de Tendencias Educativas en América Latina (SITEAL). (2009). Datos destacados. La escuela y los adolescentes. Organización de las Naciones Unidas para la educación, la ciencia y cultura.

" Terigi, F. (2009). Las trayectorias escolares. Del problema individual al desafío de la política educativa. Buenos Aires: Ministerio de Educación de la Nación.

»Waisman, M. A. (2012). Dime a quién le vendes y te diré quién eres...Relaciones entre actores relevantes y dinámica histórica en la comercialización de hortalizas en el periurbano de la ciudad de La Plata. En: Actas de las Jornadas Académicas Tierra y Movimientos Sociales en la Argentina. "A cien años del Grito de Alcorta”, Universidad Nacional de Rosario, Facultad de Humanidades y Artes, Rosario, 29, 30 y 31 de Agosto, ISBN: 978-987-677-049-1.

"Willis, P. (1988). Aprendiendo a trabajar. Cómo los chicos de clase obrera consiguen trabajos de clase obrera. España: Akal. 